\title{
Perichondrium mesenchymal stem cells inhibit the growth of breast cancer cells via the DKK-1/Wnt//-catenin signaling pathway
}

\author{
MIN LI $^{1 *}$, HUI CAI ${ }^{2}$, YA YANG $^{3}$, JIA ZHANG $^{1}$, KAI SUN $^{4}$, YAN YAN $^{1}$, HANGYING QU $^{1}$, \\ WEIWEI WANG ${ }^{5}$, JIANSHENG WANG ${ }^{1 *}$ and XIAOYI DUAN ${ }^{6^{*}}$
}

${ }^{1}$ The Second Department of Thoracic Surgery, ${ }^{2}$ Department of Vascular Surgery, The First Affiliated Hospital of
Xi'an Jiaotong University, Xi'an, Shaanxi 710061; ${ }^{3}$ The Third Department of Radiation Oncology,
The First Affiliated Hospital of Zhengzhou University, Zhengzhou, Henan 450000;
${ }^{4}$ Department of Medical Oncology, The Second Hospital of Lanzhou, Lanzhou, Gansu 730000;
${ }^{5}$ Department of Histology and Embryology, Laboratory of Stem Cell and Tissue Engineering,
Chongqing Medical University, Chongqing 400016; ${ }^{6}$ Department of Radiology,
The First Affiliated Hospital of Xi'an Jiaotong University, Xi'an, Shaanxi 710061, P.R. China

Received January 15, 2016; Accepted February 24, 2016

DOI: $10.3892 / o r .2016 .4853$

\begin{abstract}
In recent years, mesenchymal stem cells (MSCs), which possess the ability to specifically home to tumor sites, with the potential of multi-directional differentiation and low immunogenicity, have been reported to inhibit the growth of various types of tumors. In the present study, we isolated MSCs from the rib perichondrium (PMSCs). By comparing PMSCs with bone marrow-derived mesenchymal stem cells (BMSCs), we demonstrated that PMSCs present biological characteristics similar to those of BMSCs. Furthermore, we explored the effect and antitumor mechanism of PMSCs in rat SHZ- 88 breast cancer cells. The growth, migration and invasion of the SHZ-88 cells were significantly inhibited, and the $\mathrm{Wnt} / \beta$-catenin pathway and its target genes were downregulated in the SHZ-88 cells by PMSC-conditioned medium. The expression level of dickkopf-1 (DKK-1) was higher in the PMSCs than that noted in the SHZ-88 cells. Neutralization of DKK-1 in the PMSC-conditioned medium attenuated the
\end{abstract}

Correspondence to: Professor Xiaoyi Duan, Department of Radiology, The First Affiliated Hospital of Xi'an Jiaotong University, 277 West Yanta Road, Xi'an, Shaanxi 710061, P.R. China

E-mail: duanxy@mail.xjtu.edu.cn

Professor Jiansheng Wang, The Second Department of Thoracic Surgery, The First Affiliated Hospital of Xi'an Jiaotong University, 277 West Yanta Road, Xi'an, Shaanxi 710061, P.R. China

E-mail:wangjsh@mail.xjtu.edu.cn

${ }^{*}$ Contributed equally

Key words: biological characteristics, breast cancer, perichondrium mesenchymal stem cells, signaling pathway inhibitory effects of PMSCs on SHZ-88 cells. Therefore, PMSC-secreted DKK-1 is involved in the inhibition of SHZ-88 cell growth, migration and invasion, via the $\mathrm{Wnt} / \beta$-catenin signaling pathway. In addition, we demonstrated that PMSCs inhibited the growth of breast cancer in vivo and prolonged the survival time of tumor-bearing rats. PMSCs inhibited the growth of transplanted breast tumors through the Wnt/ $\beta$ catenin signaling pathway. In conclusion, our data confirmed that MSCs derived from the perichondrium present biological characteristics similar to those of BMSCs and inhibit the growth of breast cancer cells through the Wnt/ $\beta$-catenin signaling pathway in vitro and in vivo. DKK-1 secreted by PMSCs played a vital role in controlling the Wnt/ $\beta$-catenin signaling pathway in breast cancer.

\section{Introduction}

Mesenchymal stem cells (MSCs), known as pluripotent stem cells, were initially isolated from the bone marrow and named bone marrow-derived mesenchymal stem cells (BMSCs) (1-3). In-depth analysis has been performed for BMSCs $(4,5)$, which exist in a wide range of tissues $(6-8)$. Many researchers $(6,8,9)$ believe that MSCs originate from adult stem cells.

MSCs possess the ability of self-renewal, multiple differentiation potential, specific homing to tumors, and low immunogenicity $(3,10,11)$. MSCs are being used increasingly for cancer treatment (12-14). Various reports state that MSCs can promote the progression of breast cancer and colon cancer $(15,16)$. Other reports have demonstrated that MSCs can inhibit the growth of pancreatic cancer, Kaposi's sarcoma and breast cancer $(13,17,18)$. In breast cancer, the effect of MSCs is controversial. Studies reported that the regulated selfrenewal of stem cells mediated by the Wnt/ $\beta$-catenin signaling pathway might be subverted in cancer cells to allow malignant proliferation $(19,20)$. Likewise, the stem cell microenviron- 
ment plays an essential role in preventing carcinogenesis by inhibiting proliferation (21). MSCs were found to inhibit tumor proliferation through secretion of dickkopf-1 (DKK-1), which acts as an inhibitor of the Wnt/ $\beta$-catenin signaling pathway (22).

The rat rib perichondrium contains osteoprogenitor cells, a type of adult stem cells. In the present study, we first determined whether MSCs could be isolated from the perichondrium and whether perichondrium MSCs (PMSCs) present biological characteristics similar to those of BMSCs. We next explored the effect of PMSCs on rat SHZ-88 breast cancer cells in vitro and in vivo. We also investigated whether PMSCs affect breast cancer cells through the DKK-1/Wnt/ $\beta$-catenin signaling pathway. Our findings demonstrated that MSCs could be derived from the perichondrium and that they inhibited the growth of SHZ- 88 breast cancer cells through the DKK-1/Wnt/ $\beta$-catenin signaling pathway.

\section{Materials and methods}

Cell culture. Specific pathogen-free 4-week-old female Sprague-Dawley (SD) rats were obtained from the Experimental Animal Center of Xi'an Jiaotong University School of Medicine. All animals were cared for in accordance with the institutional guidelines for the use of experimental animals. The perichondrium was separated under a dissecting microscope and treated with $5 \mathrm{ml}$ of $0.2 \%$ collagenase II (Sigma-Aldrich St. Louis, MO, USA) for $3 \mathrm{~h}$ in a $37^{\circ} \mathrm{C}$ incubator shaker. We then collected the supernatant via 200 mesh sieves and added $1 \mathrm{ml}$ fetal bovine serum (FBS; HzSjq Co., Ltd., Hangzhou, China) to stop the digestion. After centrifugation at $1,200 \mathrm{x}$ g for $10 \mathrm{~min}$, the perichondrium cells were cultured in Dulbecco's modified Eagle's medium (DMEM)/F12 (HyClone Co., Logan, UT, USA) with 10\% FBS. Bone marrow cells were isolated from femurs and tibias as previously described (8), and cultured in DMEM/F12 with $10 \%$ FBS. SHZ-88 cells were obtained from Shanghai Cell Research Institute (Shanghai, China) and cultured in Roswell Park Memorial Institute (RPMI)-1640 medium (HyClone) with $10 \%$ newborn calf serum (NBCS; HzSjq Co. Ltd.) and $100 \mu \mathrm{g} / \mathrm{ml}$ penicillin/streptomycin (Gibco Life Technologies, Rockville, MD, USA). All cell lines were maintained in a humidified atmosphere at $37^{\circ} \mathrm{C}$ with $5 \% \mathrm{CO}_{2}$ and routinely passaged using trypsin (Invitrogen, Camarillo, CA, USA) when nearly confluent.

Immunofluorescence staining. The primary to 3rd-generation perichondrium cells and BMSCs were seeded at $4 \times 10^{5} / \mathrm{ml}$ in 24 -well plates covered with glass slides. When $70 \%$ confluency was reached, the slides were removed and the cells were fixed with $4 \%$ paraformaldehyde phosphate-buffered saline (PBS) for $30 \mathrm{~min}$ and stained with the following primary antibodies overnight at $4^{\circ} \mathrm{C}$ : anti-type II collagen rabbit polyclonal antibody (bs-8859R), anti-CD34 rabbit polyclonal antibody (bs-0646R), anti-CD90 rabbit polyclonal antibody (bs-0778R) (1:200 dilution), and anti-CD105 antibody rabbit polyclonal (bs-0579R; 1:100 dilution) (both from Bioss Biological Technology Co., Beijing, China). They were then incubated with the conjugated secondary CY3 antibody (BA1032; 1:500 dilution; Boster Biological Technology Co., Wuhan, China).
4',6-Diamidino-2-phenylindole (DAPI; C-0033; 1:10,000 dilution; Bioss) was used to stain the cell nuclei.

Adipogenic and osteogenic differentiation. The 3rd-generation PMSCs and BMSCs were seeded at $4 \times 10^{4} / \mathrm{ml}$ in $24-$ well plates covered with glass slides. After 3 days, we changed the culture medium to the corresponding conditioned medium for adipogenic or osteogenic differentiation (23-26). After 14 days of adipogenic and 21 days of osteogenic induction, the slides were removed and the cells were fixed for $30 \mathrm{~min}$ with $4 \%$ paraformaldehyde. The lipid droplets were stained by Oil Red $\mathrm{O}$ (Sigma-Aldrich). The mineralization nodes were stained by $5 \%$ silver nitrate (Sigma-Aldrich) and exposed to an ultraviolet lamp within $60 \mathrm{~min}$. Hematoxylin was used to stain the cell nuclei.

Treatment of SHZ-88 cells with conditioned medium derived from PMSCs. The 3rd-generation PMSCs were cultured as indicated above. When the cells grew to full confluency, the medium was replaced by serum-free medium for $48 \mathrm{~h}$. The supernatants derived from the PMSC cultures were harvested by centrifugation at $800 \mathrm{x}$ f for $5 \mathrm{~min}$. The SHZ- 88 cells were treated with a mixture of RPMI-1640 and PMSC-conditioned medium (5:5) containing 10\% NBCS for $72 \mathrm{~h}$, during which time, the culture medium was replaced every $24 \mathrm{~h}$. SHZ-88 cells were cultured in normal medium as a control group. To neutralize DKK-1, PMSC-conditioned medium was incubated with rabbit-anti-DKK-1 polyclonal antibody (Bioworld Technology, Inc., St. Louis Park, MN, USA) at a final concentration of $100 \mathrm{ng} / \mathrm{ml}$ at $4^{\circ} \mathrm{C}$ for $24 \mathrm{~h}(27,28)$, and subsequently used to treat SHZ-88 cells for $72 \mathrm{~h}$. Normal rabbit IgG was used as a negative control.

Cell proliferation assessment. Colorimetric 3-(4,5-dimethylthiazol-2-yl)-2,5-diphenyltetrazolium bromide (MTT) assay was used to assess the proliferation of cells. SHZ-88 cells $(100 \mu \mathrm{l})$ were seeded at a density of $4 \times 10^{4}$ cells $/ \mathrm{ml}$ in $96-$ well plates and treated with PMSC-conditioned medium (control without PMSC-conditioned medium) for 24, 48 and $72 \mathrm{~h}$. Ten microliters of a $5 \mathrm{mg} / \mathrm{ml}$ solution of MTT (Sigma-Aldrich) in PBS was added to each well and the plates were incubated for $4 \mathrm{~h}$ at $37^{\circ} \mathrm{C}$. One hundred fifty microliters of dimethylsulfoxide (Sigma, St. Louis, MO, USA) was added to each well and the plates were shaken for $15 \mathrm{~min}$ before reading the optical density (OD) of each well at $570 \mathrm{~nm}$ on a microplate reader.

Cell migration and invasion assays. After treatment of SHZ-88 cells with $50 \%$ PMSC-conditioned medium for $48 \mathrm{~h}$, migration and invasion assays were conducted using Transwell plates with $8-\mu \mathrm{m}$ pore size membranes (Millipore Inc., Billerica, MA, USA) as previously described $(29,30)$. After incubation for $16 \mathrm{~h}$ (for migration assays) or $24 \mathrm{~h}$ (for invasion assays), cells remaining on the upper side of the filter were removed with cotton swabs. The cells that attached to the lower surface were fixed, stained using crystal violet and washed with PBS. Cells were counted in five high-power fields/membrane. The results are presented as the mean number of cells that migrated per field per membrane. All experiments were conducted in triplicate.

SHZ- 88 cell transplantation in SD rats. SHZ-88 cells in the log-phase were diluted in normal saline (NS) and were subcu- 
taneously injected into the right armpit of 10-day-old SD female rats. Every rat was injected with $5 \times 10^{5}$ cells $/ 0.2 \mathrm{ml}$. When subcutaneous tumors reached 5-8 $\mathrm{mm}$ in size, SD rats were randomly divided into PMSC and NS groups ( $\mathrm{n}=16$ rats/group). Animals in the PMSC group were injected with $3 \times 10^{6} / 0.2 \mathrm{ml}$ PMSCs (diluted in NS) via the tail vein every 3 days. Animals in the NS group were injected with $0.2 \mathrm{ml}$ NS via the tail vein every 3 day as a control group. We measured the size of subcutaneous tumors every 6 days. The tumor volume was calculated using the following formula: Tumor volume $=1 / 2($ long tumor diameter $\mathrm{x}$ short tumor diameter ${ }^{2}$ ). The tumor growth curve was drawn by plotting tumor volumes according to the time in each group. Finally, 6 rats in each group were euthanized after 30 days and tumor growth inhibitory rate was calculated using the following formula: Tumor inhibition rate $=[$ (average volume of control group - average volume of experimental group)/average volume of control group] $x 100 \%$. A piece of the tumor tissue from each animal was fixed in $4 \%$ paraformaldehyde while the remaining tumor tissue was stored at $80^{\circ} \mathrm{C}$. Surviving animals (the remaining 10 animals in each group) were observed daily for 60 days.

Western blot analyses. The proteins were extracted from the SHZ-88 cells treated with MSC-conditioned medium for $72 \mathrm{~h}$ and frozen tumors from the tumor-bearing rats according to standard procedures. Proteins were examined with specific primary antibodies: anti-DKK-1 rabbit polyclonal antibody (BS7731), anti-Bcl-2 rabbit polyclonal antibody (BS1031), anti-PCNA rabbit polyclonal antibody (BS6438), anti-survivin rabbit polyclonal antibody (BS8456) (1:1,000 dilution; Bioworld Technology), anti- $\beta$-catenin rabbit polyclonal antibody (51067-2-AP) (1:500 dilution; Proteintech, Huhan, China), anti-c-Myc rabbit polyclonal antibody (10057-1-AP) (1:100 dilution; Proteintech), and anti- $\beta$-actin rabbit polyclonal antibody (bs-0061R; 1:1,000 dilution; Bioss), followed by a conjugated secondary antibody: goat-anti-rabbit IgG antibody (1:3,000 dilution; Bioss). The reactions were visualized using the enhanced chemiluminescence (ECL) reagent (Millipore). The band intensity of western blotting was measured by densitometry using the Quantity One software (Bio-Rad Laboratories, Hercules, CA, USA). The protein levels were normalized to the protein level of $\beta$-actin which was used as a loading control.

Immunohistochemical (IHC) staining. Tumor tissues fixed in $4 \%$ paraformaldehyde were processed for paraffin embedding and sectioned (5- $\mu \mathrm{m}$ thickness). Formalin-fixed paraffin-embedded tumor sections from NS and PMSC-treated animals were analyzed by IHC staining using an anti- $\beta$-catenin rabbit polyclonal antibody (1:200; Proteintech) and a biotin-conjugated secondary antibody. The staining was performed following the SP kit procedure (Golden Bridge International, Beijing, China). As a control, the primary antibody was replaced by PBS. IHC staining results were assessed independently by two pathologists in a semi-quantitative manner, scored by a semi-quantitative immunoreactivity scoring (IRS) system, and divided into high and low expression specimens.

Statistical analysis. All data are expressed as means with standard error (SE). One-way ANOVA and Student's t-test were used to test differences between the groups. The Kaplan-Meier method was used to test the survival time of tumor-bearing rats in different groups. $\mathrm{P}<0.05$ was considered to indicate a significant result. All analyses were performed using SPSS software version 18.0 (IBM, Corp., New York, NY, USA).

\section{Results}

\section{Biological characteristics of the PMSCs and BMSCs}

Growth and morphology. The primary perichondrium cells began to adhere to the plate after $12 \mathrm{~h}$ of culture. They were passaged after 5-6 days of culture when they presented a round or polygon shape (Fig. 1A). The primary bone marrow cells began to adhere to the plate after 4-5 h of culture and were passaged after 8-10 days of culture when they presented a spindle or polygon shape (Fig. 1A). As the generations increased, from 3rd-generation, two types of cells showed spindle-shape with whirlpool arrangement (Fig. 1A) and the generation times of perichondrium cells and BMSCs were 1-2 and 4-5 days, respectively. The perichondrium cells were passaged for 30 generations and retained their shape (data not shown).

Cell surface marker expression. Immunofluorescence staining indicated that type II collagen, CD34, CD90 and CD105 proteins were not expressed in primary and first generation perichondrium cells. From the 2nd-generation, cells began to express CD90 and CD105 proteins. The primary bone marrow cells were weakly positive for CD34, CD90 and CD105 proteins, but not for type II collagen. Subsequently, the cells only expressed CD90 and CD105 proteins. From the 3rd-generation, the two cell types did not expressed type II collagen and CD34 proteins, but strongly expressed CD90 and CD105 proteins (Fig. 1B). The 30th generation of perichondrium cells still strongly expressed CD90 and CD105, but did not expressed CD34 and type II collagen (data not shown).

Multipotent differentiation ability. No change in term of the induction of differentiation was observed in the control group (Fig. 1C). After 14 days of adipogenic induction of the 3rd-generation cells, perichondrium cells and BMSCs became round. Lipid droplets were observed in the cytoplasm of these cells after Oil Red O staining (Fig. 1C). After 21 days of osteogenic induction, the perichondrium cells grew as a stratified layer, some black mineralized nodules stained by silver nitrate were observed on the cell surface (Fig. 1C). BMSCs grew as a simple layer, but mineralized nodules gathered as bone nodules (Fig. 1C). The 30th generation perichondrium cells still presented lipid droplets and black mineralized nodules after induction (data not shown).

PMSC-conditioned media inhibits SHZ-88 cell growth, migration and invasion. Human MSCs can inhibit tumor growth $(22,28)$. However, no study has reported such information regarding PMSCs. In the present study, we explored the effect of PMSCs on breast cancer. The stem cell microenvironment plays an essential role in preventing carcinogenesis by inhibiting proliferation (21). Thus, we investigated the inhibitory effect of 50\% PMSC-conditioned medium on SHZ-88 cells in vitro. MTT assay showed that PMSC-conditioned medium inhibited the proliferation of SHZ-88 cells in a time-dependent 
A

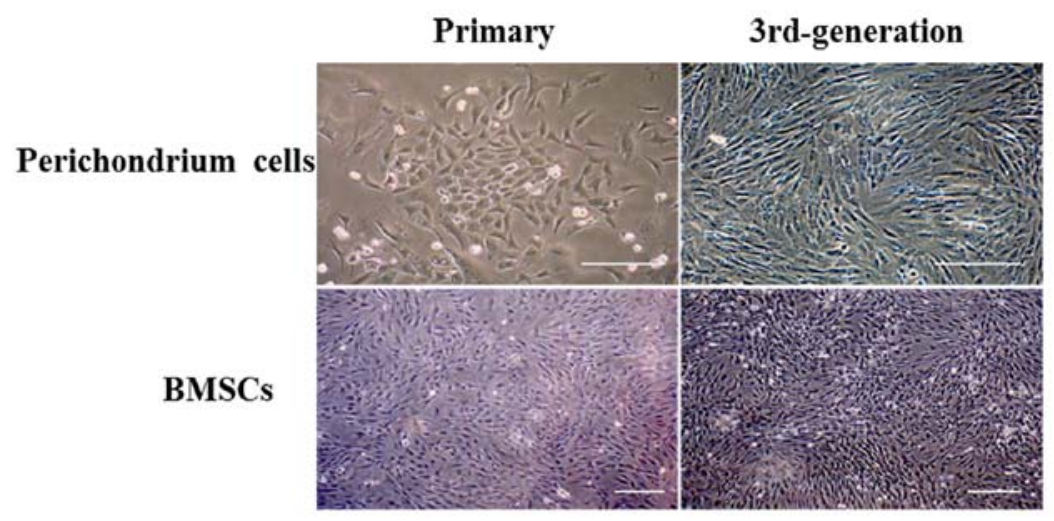

B

II collagen
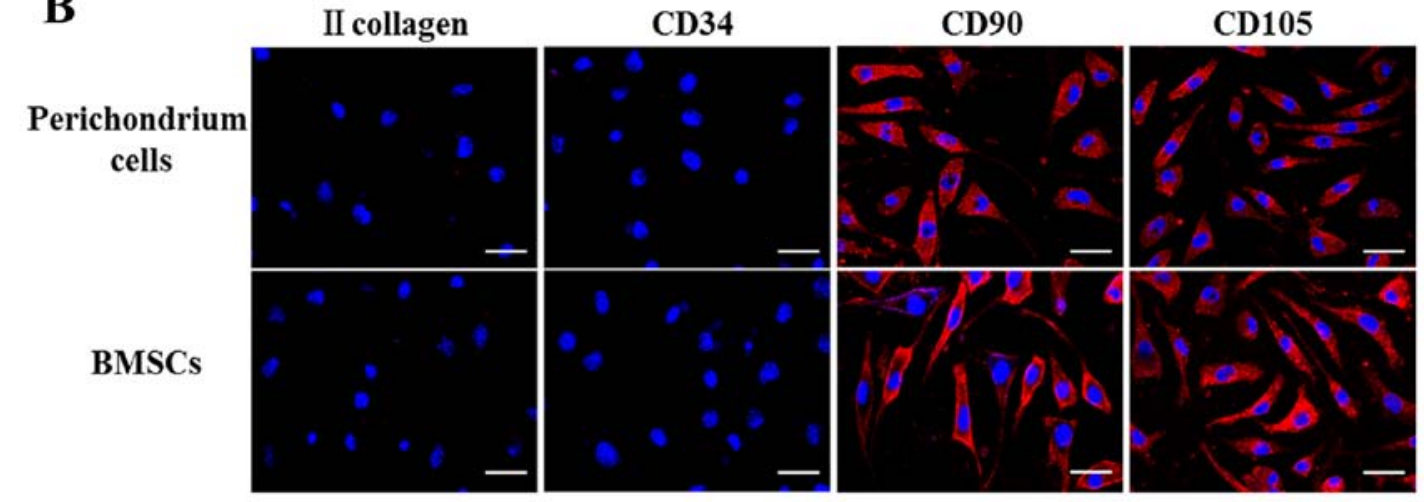

C

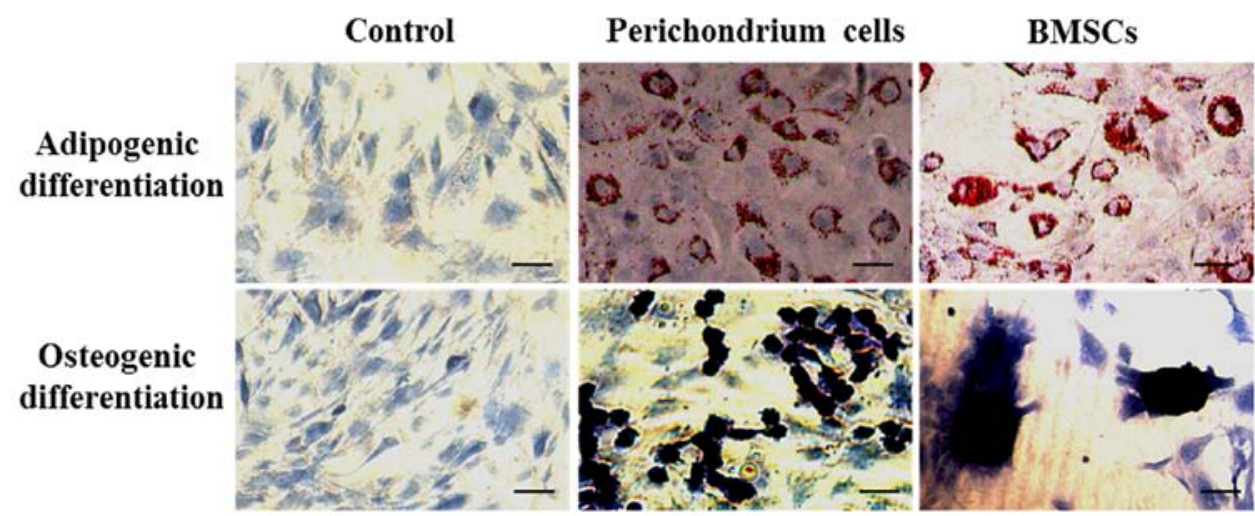

Figure 1. Biological characteristics of the perichondrium cells and BMSCs. (A) Morphology of the primary and 3rd-generation perichondrium cells and BMSCs. Scale bar, $300 \mu \mathrm{m}$. (B) Surface markers in perichondrium cells and BMSCs. The expression of type II collagen, CD34, CD90 and CD105 proteins in the 3rd-generation cells by immunofluorescence staining. Scale bar, $50 \mu \mathrm{m}$. (C) Multipotent differentiation ability of perichondrium cells and BMSCs. Adipogenic and osteogenic differentiation of the 3rd-generation cells assessed by Oil Red $\mathrm{O}$ and silver nitrate staining, respectively. Scale bar, $50 \mu \mathrm{m}$.

manner ( $\mathrm{P}<0.001$ at $72 \mathrm{~h}$; Fig. 2A). To further analyze the effect of $50 \%$ PMSC-conditioned medium on SHZ-88 cells, cell migration and invasion assays were conducted after treating SHZ-88 cells with 50\% PMSC-conditioned medium for $48 \mathrm{~h}$ in vitro. SHZ-88 cell migration and invasion were significantly reduced by the PMSC-conditioned medium $(\mathrm{P}<0.001$; Fig. 2B and C). These data suggested that some factors in the conditioned medium from PMSCs were responsible for the inhibition of tumor cell proliferation, migration and invasion.

The Wnt/ $\beta$-catenin signaling pathway is suppressed in the SHZ-88 cells treated with PMSC-conditioned medium. Studies have indicated that the self-renewal of stem cells by the Wnt/ $\beta$-catenin signaling pathway was subverted in cancer cells, resulting in tumor progression $(19,20)$. The Bcl-2,
c-Myc, PCNA and survivin genes are all targets of the Wnt/ $\beta$ catenin signaling pathway. Western blot analysis showed that $\beta$-catenin, Bcl-2, c-Myc, PCNA and survivin proteins were downregulated in SHZ-88 cells treated with 50\% PMSCconditioned medium $(\mathrm{P}<0.001$; Fig. 3$)$. These results indicated that some soluble exocrine factors in the MSC-conditioned medium are involved in the inhibition of the $\mathrm{Wnt} / \beta$-catenin signaling pathway in SHZ-88 cells.

DKK-1 derived from PMSCs contributes to the inhibition of SHZ-88 cells. MSCs have been shown to inhibit tumor proliferation by secreting DKK-1, which acts as an inhibitor of the Wnt/ $\beta$-catenin signaling pathway $(28,31)$. Thus, we determined the expression levels of DKK-1 in the SHZ-88 cells and PMSCs. Western blot analysis indicated that the 
A

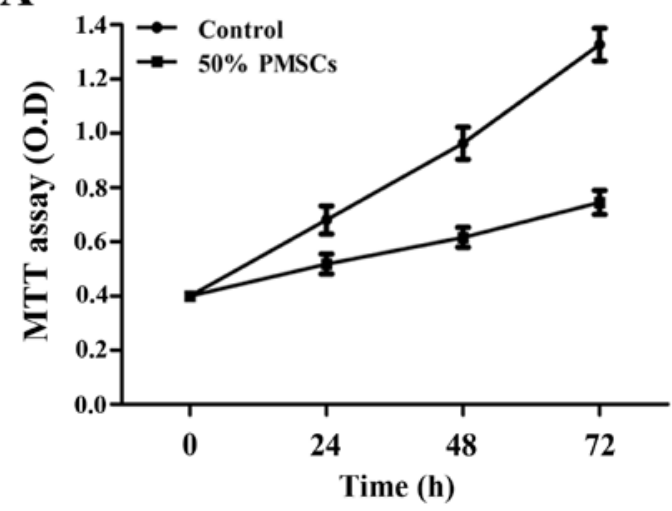

B
C

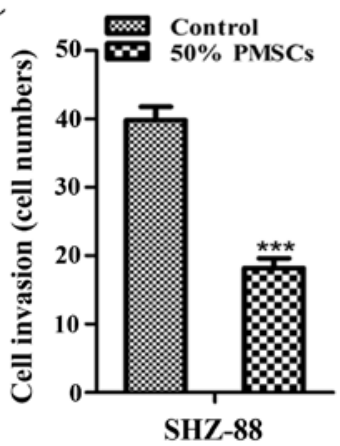

$50 \%$ PMSCs
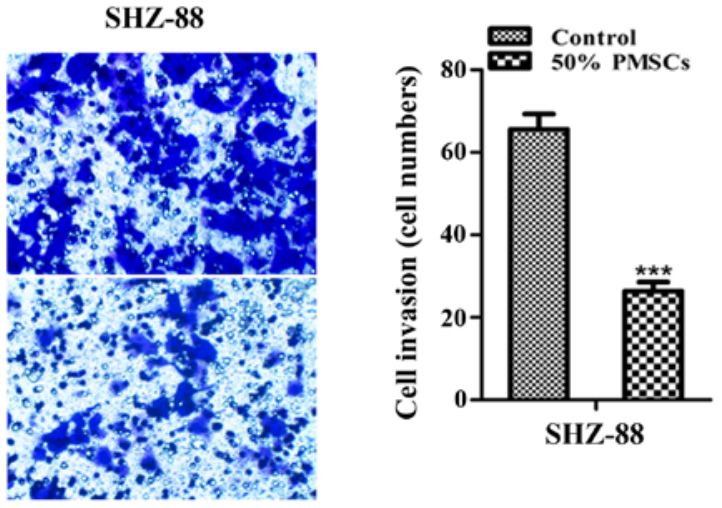

Figure 2. Inhibitory effect of PMSC-conditioned medium on SHZ-88 cells. (A) MTT assay showed that the growth of SHZ- 88 cells was reduced in the presence of 50\% PMSC-conditioned medium for $72 \mathrm{~h}(\mathrm{P}<0.001)$. (B and $\mathrm{C})$ Cell Transwell assays were conducted to investigate the effect of PMSC-conditioned medium on breast cancer cell migration (B) and invasion (C). The results are presented as the mean $\pm \mathrm{SE}$ of cell numbers obtained in three independent experiments $\left({ }^{* * *} \mathrm{P}<0.001\right)$.
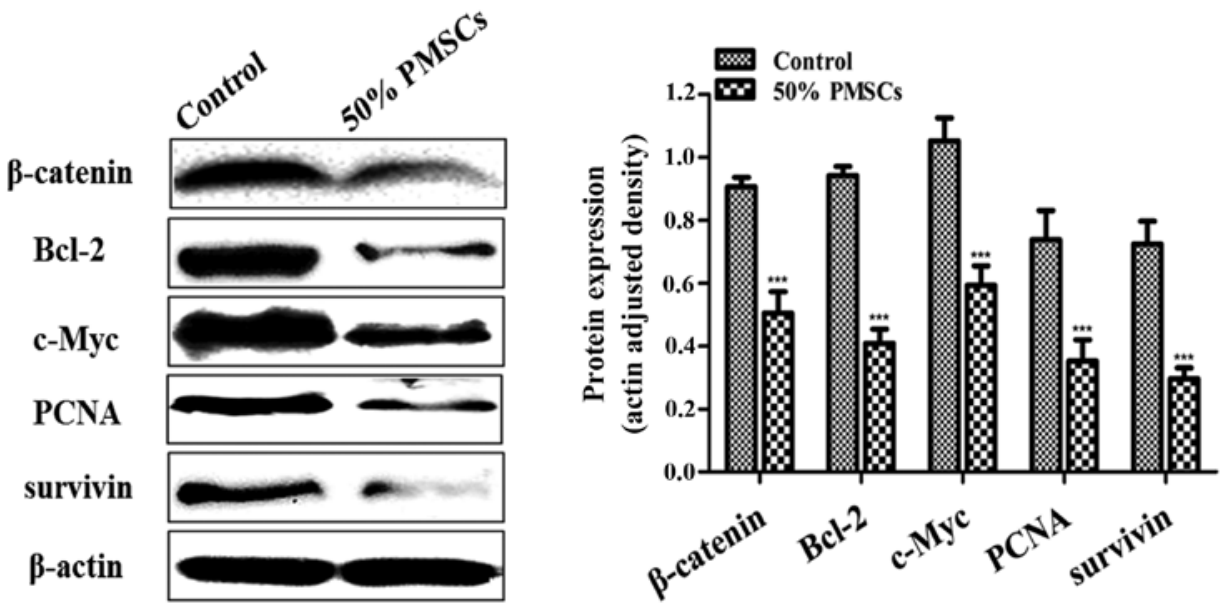

Figure 3. Effect of PMSC-conditioned medium on the Wnt/ $\beta$-catenin signaling pathway of tumor cells in vitro. Western blot analyses showed that $\beta$-catenin, $\mathrm{Bcl}-2$, c-Myc, PCNA and survivin were downregulated in the SHZ-88 cells treated with 50\% PMSC-conditioned medium $\left({ }^{* * *} \mathrm{P}<0.001\right)$.

DKK-1 expression level was higher in the PMSCs than that in the SHZ-88 cells $(\mathrm{P}<0.001$; Fig. 4A). DDK-1 neutralization by the rabbit antibody against the rat DKK-1 in the PMSCconditioned medium abolished the inhibitory effect of the PMSC-conditioned medium on SHZ-88 cell proliferation as demonstrated by MTT assay ( $\mathrm{P}>0.05$; Fig. 4B). In addition, the inhibitory effect of the PMSC-conditioned medium on migration and invasion of SHZ-88 cells was also lost $(\mathrm{P}>0.05$; Fig. 4C and D). Moreover, western blot analysis indicated that neutralization of DKK-1 in the PMSC-conditioned medium abrogated the downregulating effect of the conditioned medium on the expression of $\beta$-catenin, Bcl-2, c-Myc, PCNA and survivin in SHZ-88 cells ( $\mathrm{P}>0.05$; Fig. 4E). These data indicated that the inhibition of SHZ-88 cell growth, migra- 
A

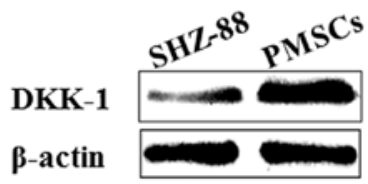

B

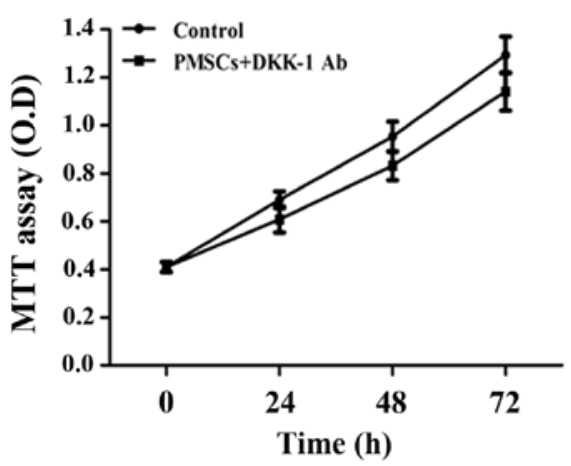

D

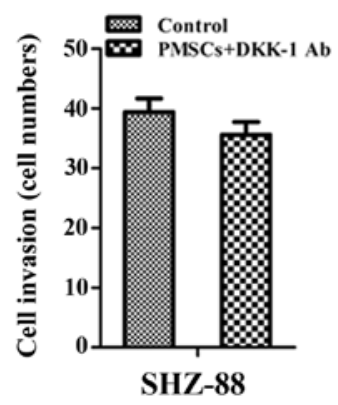

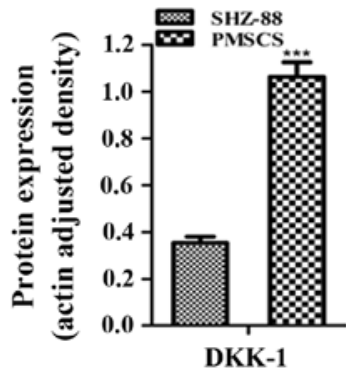

C
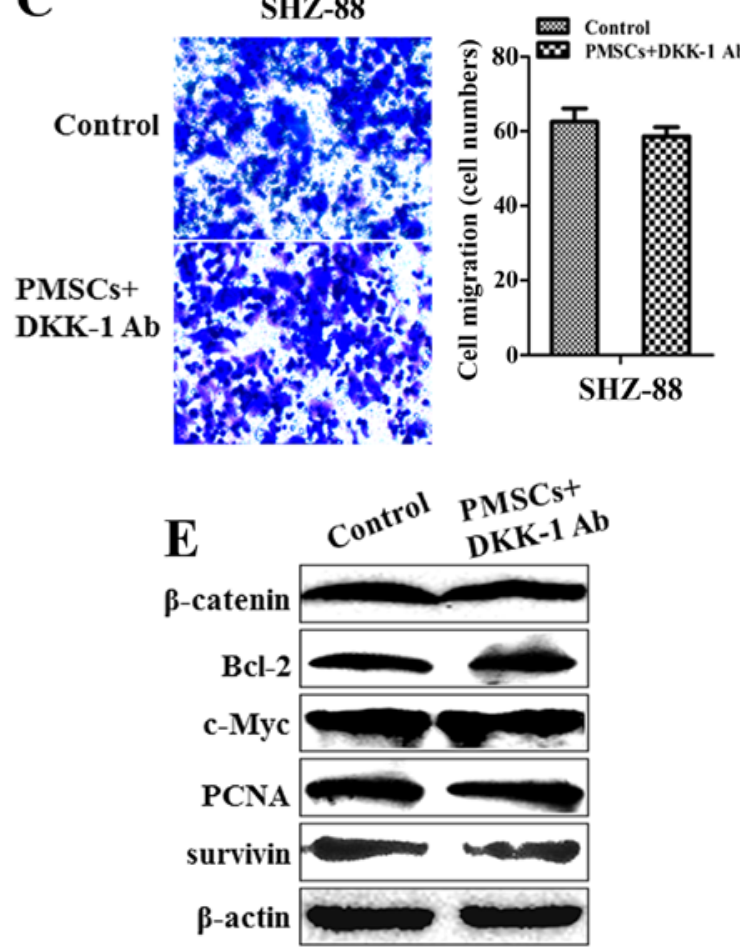

Figure 4. Effect of DKK-1 secreted by PMSCs on tumor cells. (A) Western blot analyses showed that DKK-1 expression level was higher in PMSCs than that in the SHZ-88 cells $\left({ }^{* * *} \mathrm{P}<0.001\right)$. (B) Reduction of SHZ-88 cell proliferation by exposure to PMSC-conditioned medium was abolished by neutralization of DKK-1 with a rabbit anti-DKK-1 antibody $(\mathrm{P}>0.05)$. (C and D) Transwell assays show that PMSC-conditioned medium lost its ability to reduce migration $(\mathrm{C})$ and invasion (D) in SHZ-88 cells after DKK-1 neutralization (P>0.05). (E) Western blot analyses revealed that the downregulating effect of PMSC-conditioned medium on $\beta$-catenin, Bcl-2, c-Myc, PCNA and survivin expression in SHZ-88 cells was attenuated by DKK-1 neutralization.

tion and invasion mediated by PMSC-conditioned medium involved DKK-1 secreted by PMSCs in the medium.

\section{PMSCs inhibit the growth of breast cancer in vivo}

PMSCs inhibit the growth of transplanted tumors. To determine the effect of PMSCs on transplanted tumors in vivo, we established a subcutaneous tumor model of breast cancer in $\mathrm{SD}$ rats. When the tumor nodules reached 5-8 $\mathrm{mm}$ in length, the rats were injected with either PMSCs or NS (control group). Tumor volume gradually increased and the tumor growth rate was faster in the NS group than that determined in the PMSC group. On day 30, no necrosis was observed in the tumors from rats treated with PMSCs, while partial necrosis and a hemorrhagic tendency on the surface of tumors were observed in the tumors from rats treated with NS. Additionally, the size of the tumors in the NS group was larger than that of the tumors from the PMSC group (Fig. 5A). We measured the size of the subcutaneous tumors every 6 days and constructed the tumor growth curve based on tumor volumes (Fig. 5A). The tumor inhibition rate in the PMSC group reached $62.8 \%$. These data indicated that treatment of the rats with PMSCs resulted in a significant growth inhibition in vivo when compared with the control group $(\mathrm{P}<0.001)$. The mean survival time of the rats in the NS group was $39.7 \pm 1.2$ days, while that of the rats in the PMSC group was 53.4 \pm 2.0 days. The survival time of the rats in the NS group was significantly shorter than that of the rats treated with PMSCs $(\mathrm{P}<0.001$; Fig. 5B).

PMSCs inhibit the growth of transplanted tumors via the $W n t / \beta$-catenin signaling pathway. We further investigated the molecular mechanisms underlying the inhibitory effect of PMSCs on breast cancer. Immunohistochemistry staining indicated that the $\beta$-catenin protein in the tumors from rats treated with PMSCs was expressed at low levels, while it was highly expressed in the tumors of rats treated with NS when using the IRS system (Fig. 5C). Western blot analyses showed that $\beta$-catenin, Bcl-2, $\mathrm{c}-\mathrm{Myc}, \mathrm{PCNA}$ and survivin proteins were downregulated in the PMSC group $(\mathrm{P}<0.001$; Fig. 5D). These results indicated that PMSCs inhibited the growth of 
A

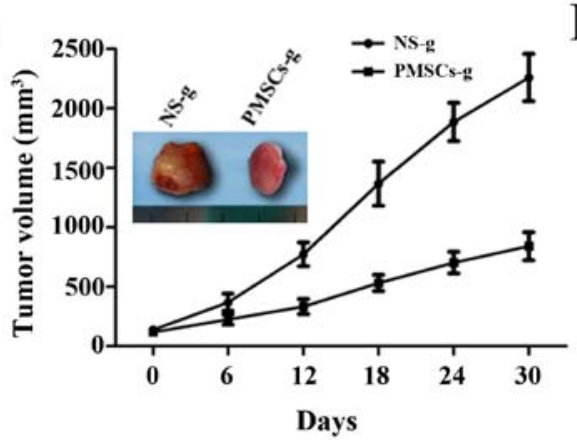

C

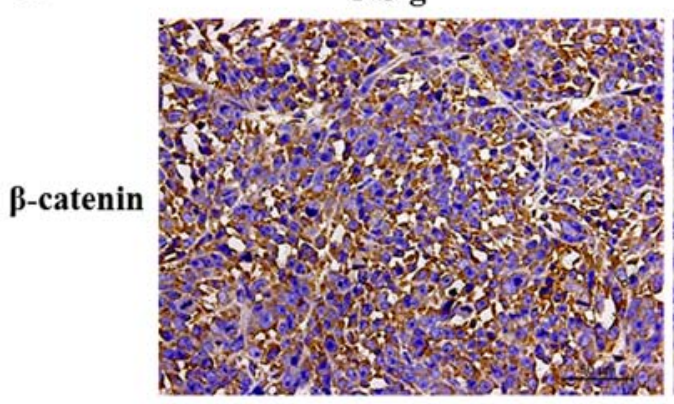

B
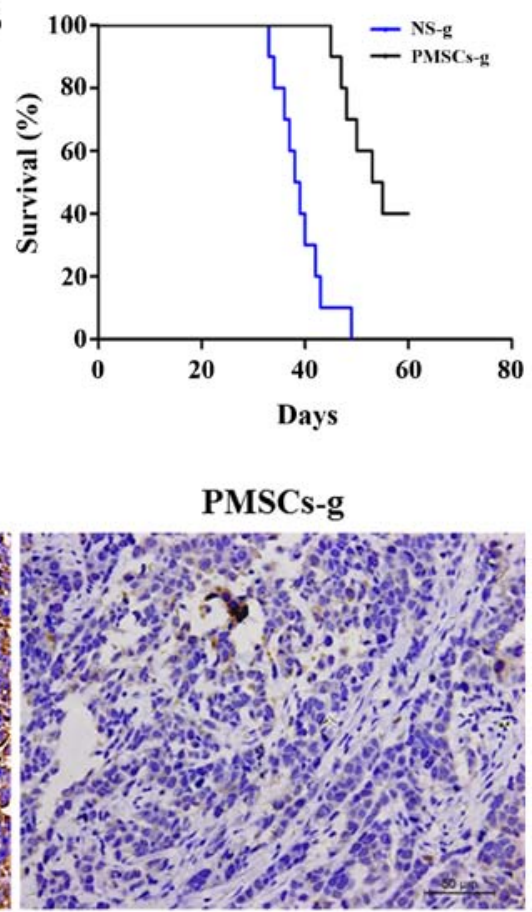

D
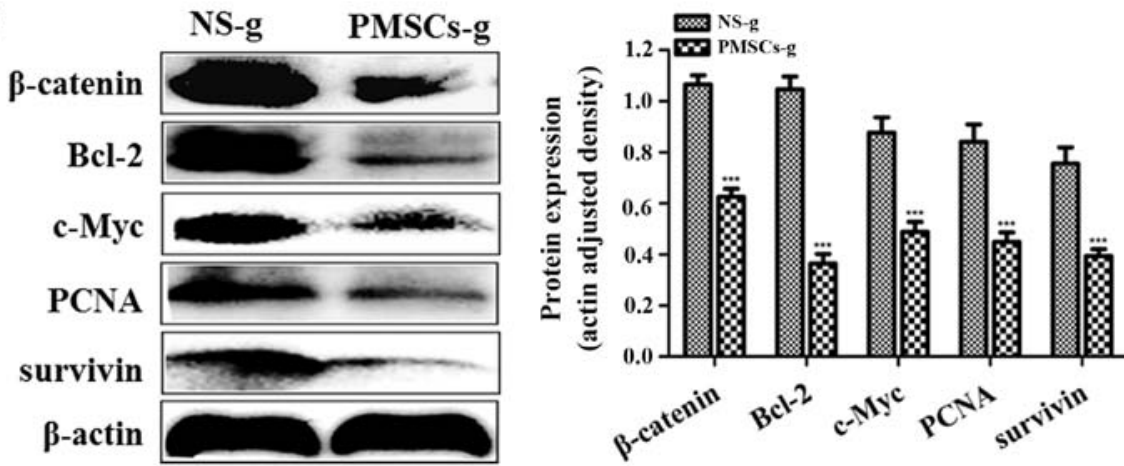

Figure 5. Effect of PMSCs on the growth of transplanted tumors. (A) Tumors from the NS group were larger than those from the PMSC group. The tumor growth curve was obtained by plotting the tumor volumes according to time. Treatment of the rats with PMSCs for 30 days resulted in a significant growth inhibition on tumor growth in vivo when compared with the NS group $(\mathrm{P}<0.001)$. (B) Kaplan-Meier survival curves of tumor-bearing rats in the NS and PMSC groups. Tumor-bearing rats in the NS group presented a poorer overall survival, while tumor-bearing rats treated with PMSCs presented a higher overall survival. The survival time of the animals in the NS group was significantly shorter than that of the rats treated with PMSCs $(\mathrm{P}<0.001)$. (C and D) Effect of PMSCs on the Wnt/ $\beta$-catenin signaling pathway in tumors in vivo. (C) Immunohistochemistry staining showed that the $\beta$-catenin expression level in the tumors from rats treated with PMSCs was low, while it was high in the tumors from rats treated with NS. (D) Western blot analyses showed that $\beta$-catenin, Bcl-2, c-Myc, PCNA and survivin were downregulated in the tumors from rats treated with PMSCs $\left({ }^{* * * *} \mathrm{P}<0.001\right)$.

transplanted tumors via the Wnt/ $\beta$-catenin signaling pathway in vivo.

\section{Discussion}

Many researchers $(8,10,14)$ believe that MSCs originate from adult stem cells. The rib perichondrium contains osteoprogenitor cells, a type of adult stem cells. In the present study, we investigated whether MSCs could be isolated from the perichondrium. Our results showed that, from the 3rd-generation, the perichondrium cells presented a typical spindle-shape with whirlpool arrangement and strongly expressed CD90 and CD105 proteins (32). Additionally, adipogenic and osteogenic differentiation could be induced in these cells. These data demonstrated that perichondrium cells presented biological characteristics similar to those of
BMSCs. These findings strongly suggest that we successfully derived stem cells from the rib perichondrium, which were named PMSCs.

MSCs possess the ability to specifically home to tumors and to self-renew, and present low immunogenicity $(3,10,11,16)$. Thus, they have been used for cancer treatment $(13,33,34)$. However, the effects of MSCs on tumors are controversial. Various reports state that MSCs promote the progression of breast cancer and colon cancer cells $(15,16)$. Other reports indicate that MSCs can inhibit the growth of pancreatic cancer, Kaposi's sarcoma, and breast cancer cells $(13,17,18)$. In the present study, using MTT, cell migration and invasion assays, we found that PMSC-conditioned medium inhibited the growth, migration and invasion of SHZ-88 cells $(\mathrm{P}<0.001)$. Our findings are consistent with several reports $(18,35)$. The Wnt/ $\beta$-catenin signaling pathway plays an important role 
in the self-renewal of stem cells (19), but abnormal activation of the $\mathrm{Wnt} / \beta$-catenin signaling pathway can lead to human cancer (20). The $\mathrm{Wnt} / \beta$-catenin pathway is related to the efficacy of MSCs in suppressing hepatoma and breast cancer $(18,28,35)$. The $B c l-2, c-M y c, P C N A$ and survivin genes are all targets of the $\mathrm{Wnt} / \beta$-catenin signaling pathway $(36,37)$. In the present study, western blot analyses confirmed that the Wnt/ $\beta$-catenin signaling pathway in SHZ-88 cells was blocked by PMSC-conditioned medium. These results are consistent with the above report. These data suggest that various soluble factors in PMSC-conditioned medium are responsible for the inhibition of the growth, migration, invasion and $\mathrm{Wnt} / \beta$-catenin signaling pathway in SHZ-88 cells.

Next, we attempted to identify the inhibitors of the Wnt/ $\beta$-catenin signaling pathway in the PMSC-conditioned medium. It was previously reported that MSCs inhibit tumor proliferation via secretion of DKK-1, which acts as a negative regulator of the Wnt/ $\beta$-catenin signaling pathway $(22,28)$. Accordingly, we speculated that DKK-1 secreted by PMSCs was involved in the inhibition of the $\mathrm{Wnt} / \beta$-catenin signaling pathway in SHZ-88 cells. Western blot analyses showed that DKK-1 expression level in PMSCs was higher than that in SHZ-88 cells, which provided evidence that DKK-1 from PMSCs may play a vital role in controlling the Wnt/ $\beta$-catenin signaling in SHZ-88 cells. These findings are consistent with various reports $(18,22,28)$. In order to further confirm the role of DKK-1 secreted by PMSCs in the inhibition of the Wnt/ $\beta$-catenin signaling pathway in SHZ-88 cells, we neutralized DKK-1 in the PMSC-conditioned medium using an antibody against DKK-1 and demonstrated that the inhibition of SHZ-88 cell growth, migration and invasion mediated by PMSC-conditioned medium was reduced by DKK-1 neutralization. Additionally, the treated conditioned medium lost the ability to downregulate the expression of $\beta$-catenin, Bcl-2, c-Myc, PCNA and survivin in SHZ-88 cells. This provided evidence that DKK-1 secreted by PMSCs contributed to the inhibition of the Wnt/ $\beta$-catenin signaling pathway in SHZ-88 cells. Moreover, we showed that PMSCs inhibited the growth of transplanted tumors in vivo. When compared with the NS group, injection of PMSCs significantly inhibited tumor growth and prolonged the survival time of tumor-bearing rats. Wnt/ $\beta$-catenin and its target genes were downregulated in the tumors from rats treated with PMSCs. These results indicate that PMSCs inhibit the growth of transplanted breast tumors through the Wnt/ $\beta$-catenin signaling pathway as observed in vivo.

In summary, the present study is the first to report the isolation of mesenchymal stem cells from the perichondrium (PMSCs) of rat. Furthermore, PMSCs were found to inhibit breast cancer cell growth through the DKK-1/Wnt/ $\beta$-catenin signaling pathway. The present study provided novel information, which can be useful for the development of new therapeutics for breast cancer treatment.

\section{Acknowledgements}

The authors would like to thank Chen Huang of the Department of Genetics and Molecular Biology, Medical School, Xi'an Jiaotong University for his technical support. The present study was supported by a grant from the National Natural Science Foundation of China (no. 81471710).

\section{References}

1. Friedenstein AJ, Piatetzky-Shapiro II and Petrakova KV: Osteogenesis in transplants of bone marrow cells. J Embryol Exp Morphol 16: 381-390, 1966.

2. Friedenstein AJ, Petrakova KV, Kurolesova AI and Frolova GP: Heterotopic of bone marrow. Analysis of precursor cells for osteogenic and hematopoietic tissues. Transplantation 6: 230-247, 1968.

3. Caplan AI: Mesenchymal stem cells. J Orthop Res 9: 641-650, 1991.

4. Xia Z, Zhang C, Zeng Y, Wang T and Ai G: Transplantation of BMSCs expressing $\mathrm{hVEGF}_{165} / \mathrm{hBD} 3$ promotes wound healing in rats with combined radiation-wound injury. Int Wound $\mathbf{J} 11$ : 293-303, 2014

5. Zhang L, He A, Yin Z, Yu Z, Luo X, Liu W, Zhang W, Cao Y, Liu Y and Zhou G: Regeneration of human-ear-shaped cartilage by co-culturing human microtia chondrocytes with BMSCs. Biomaterials 35: 4878-4887, 2014.

6. Rossi B, Merlo B, Colleoni S, Iacono E, Tazzari PL, Ricci F, Lazzari $\mathrm{G}$ and Galli $\mathrm{C}$ : Isolation and in vitro characterization of bovine amniotic fluid derived stem cells at different trimesters of pregnancy. Stem Cell Rev 10: 712-724, 2014.

7. Zarrabi M, Mousavi SH, Abroun S and Sadeghi B: Potential uses for cord blood mesenchymal stem cells. Cell J 15: 274-281, 2014.

8. Yoshimura H, Muneta T, Nimura A, Yokoyama A, Koga H and Sekiya I: Comparison of rat mesenchymal stem cells derived from bone marrow, synovium, periosteum, adipose tissue, and muscle. Cell Tissue Res 327: 449-462, 2007.

9. Lu T, Hu P, Su X, Li C, Ma Y and Guan W: Isolation and characterization of mesenchymal stem cells derived from fetal bovine liver. Cell Tissue Bank 15: 439-450, 2014.

10. Reger RL, Tucker AH and Wolfe MR: Differentiation and characterization of human MSCs. In: Methods in Molecular Biology. Prockop DJ, Phinney DG, Bunnell BA (eds). pp93-107, 2008. 10.1007/978-1-60327-169-1_7.

11. Si YL, Zhao YL, Hao HJ, Fu XB and Han WD: MSCs: Biological characteristics, clinical applications and their outstanding concerns. Ageing Res Rev 10: 93-103, 2011.

12. Horwitz EM: Oncolytic virotherapy for ALL: MSCs to the rescue. Blood 123: 1286-1287, 2014.

13. Moniri MR, Dai LJ and Warnock GL: The challenge of pancreatic cancer therapy and novel treatment strategy using engineered mesenchymal stem cells. Cancer Gene Ther 21: 12-23, 2014.

14. Hong IS, Lee HY and Kang KS: Mesenchymal stem cells and cancer: Friends or enemies? Mutat Res 768: 98-106, 2014.

15. Kikuchi H, Yagi H, Hasegawa H, Ishii Y, Okabayashi K, Tsuruta M, Hoshino G, Takayanagi A and Kitagawa Y: Therapeutic potential of transgenic mesenchymal stem cells engineered to mediate anti-high mobility group box 1 activity: Targeting of colon cancer. J Surg Res 190: 134-143, 2014.

16. Goldstein RH, Reagan MR, Anderson K, Kaplan DL and Rosenblatt M: Human bone marrow-derived MSCs can home to orthotopic breast cancer tumors and promote bone metastasis. Cancer Res 70: 10044-10050, 2010.

17. Khakoo AY, Pati S, Anderson SA, Reid W, Elshal MF, Rovira II, Nguyen AT, Malide D, Combs CA, Hall G, et al: Human mesenchymal stem cells exert potent antitumorigenic effects in a model of Kaposi's sarcoma. J Exp Med 203: 1235-1247, 2006.

18. Qiao L, Xu Z, Zhao T, Zhao Z, Shi M, Zhao RC, Ye L and Zhang X: Suppression of tumorigenesis by human mesenchymal stem cells in a hepatoma model. Cell Res 18: 500-507, 2008.

19. Reya $\mathrm{T}$ and Clevers $\mathrm{H}$ : Wnt signalling in stem cells and cancer. Nature 434: 843-850, 2005.

20. Moon RT, Kohn AD, De Ferrari GV and Kaykas A: WNT and beta-catenin signalling: Diseases and therapies. Nat Rev Genet 5: 691-701, 2004.

21. Livraghi T, Meloni F, Frosi A, Lazzaroni S, Bizzarri TM, Frati L and Biava PM: Treatment with stem cell differentiation stage factors of intermediate-advanced hepatocellular carcinoma: An open randomized clinical trial. Oncol Res 15: 399-408, 2005.

22. Zhu Y, Sun Z, Han Q, Liao L, Wang J, Bian C, Li J, Yan X, Liu Y, Shao C, et al: Human mesenchymal stem cells inhibit cancer cell proliferation by secreting DKK-1. Leukemia 23: 925-933, 2009. 
23. Sekiya I, Larson BL, Vuoristo JT, Cui JG and Prockop DJ: Adipogenic differentiation of human adult stem cells from bone marrow stroma (MSCs). J Bone Miner Res 19: 256-264, 2004.

24. Jaiswal N, Haynesworth SE, Caplan AI and Bruder SP: Osteogenic differentiation of purified, culture-expanded human mesenchymal stem cells in vitro. J Cell Biochem 64: 295-312, 1997.

25. Sen A, Lea-Currie YR, Sujkowska D, Franklin DM, Wilkison WO, Halvorsen YD and Gimble JM: Adipogenic potential of human adipose derived stromal cells from multiple donors is heterogeneous. J Cell Biochem 81: 312-319, 2001.

26. Kang Y, Kim S, Bishop J, Khademhosseini A and Yang Y: The osteogenic differentiation of human bone marrow MSCs on HUVEC-derived ECM and $\beta$-TCP scaffold. Biomaterials 33 6998-7007, 2012.

27. Yamaguchi Y, Itami S, Watabe H, Yasumoto K, AbdelMalek ZA, Kubo T, Rouzaud F, Tanemura A, Yoshikawa K and Hearing VJ: Mesenchymal-epithelial interactions in the skin: Increased expression of dickkopf 1 by palmoplantar fibroblasts inhibits melanocyte growth and differentiation. J Cell Biol 165 : 275-285, 2004

28. Qiao L, Xu ZL, Zhao TJ, Ye LH and Zhang XD: Dkk-1 secreted by mesenchymal stem cells inhibits growth of breast cancer cells via depression of Wnt signalling. Cancer Lett 269: 67-77, 2008.

29. Clarke MR, Imhoff FM and Baird SK: Mesenchymal stem cells inhibit breast cancer cell migration and invasion through secretion of tissue inhibitor of metalloproteinase-1 and -2. Mol Carcinog 54: 1214-1219, 2015.
30. Huo C, Kao YH and Chuu CP: Androgen receptor inhibits epithelial-mesenchymal transition, migration, and invasion of PC-3 prostate cancer cells. Cancer Lett 369: 103-111, 2015.

32. Fedi P, Bafico A, Nieto Soria A, Burgess WH, Miki T, Bottaro DP, Kraus MH and Aaronson SA: Isolation and biochemical characterization of the human Dkk-1 homologue, a novel inhibitor of mammalian Wnt signaling. J Biol Chem 274: 19465-19472, 1999.

33. Screven R, Kenyon E, Myers MJ, Yancy HF, Skasko M, Boxer L, Bigley EC III, Borjesson DL and Zhu M: Immunophenotype and gene expression profile of mesenchymal stem cells derived from canine adipose tissue and bone marrow. Vet Immunol Immunopathol 161: 21-31, 2014.

34. Du J, Zhang Y, Xu C and Xu X: Apoptin-modified human mesenchymal stem cells inhibit growth of lung carcinoma in nude mice. Mol Med Rep 12: 1023-1029, 2015.

35. Kolluri KK, Laurent GJ and Janes SM: Mesenchymal stem cells as vectors for lung cancer therapy. Respiration 85: 443-451, 2013.

36. Abdel aziz MT, El Asmar MF, Atta HM, Mahfouz S, Fouad HH, Roshdy NK, Rashed LA, Sabry D, Hassouna AA and Taha FM: Efficacy of mesenchymal stem cells in suppression of hepatocarcinorigenesis in rats: Possible role of Wnt signaling. J Exp Clin Cancer Res 30: 49, 2011.

37. Joubert A, Bianchi P, Maritz $C$ and Joubert F: Influence of prostaglandin A2 on Bax, Bcl-2 and PCNA expression in MCF-7 cells. Biomed Res 27: 157-162, 2006. 